\title{
Tartessos-Tarshish was the model for Plato's Atlantis
}

\author{
Rainer W. Kühne
}

Tuckermannstr. 35, 38118 Braunschweig, Germany

\begin{abstract}
Literary evidence supports the following view. Tartessos and Tarshish were identical. Tartessos was the model for Plato's Atlantis. The Tartessians traded with precious metals, especially with silver. Among their trade partners were the Phoenicians, the Hebrews, and the Greeks. The capital of Tartessos lay in the Donana National Park. Tartessos existed from the tenth to the sixth century BC.
\end{abstract}

\section{TARTESSOS}

\subsection{Sources}

We know about Tartessos by several Greek and Roman writers. These include Herodotus $(1,163 ; 4,152 ; 4,191)$, Diodorus $(5,35,4)$, Strabon $(3,1-2)$, Pliny $(3,7 ; 4,120)$, Pausanias $(6,19,3)$, and Rufius Festus Avienus (Ora Maritima 225; 284).

\subsection{Trade}

The Tartessians traded with several precious metals, especially with silver (Herodotus 4,152; Diodorus 5,35,4; Avienus 225; 284). Among their trade partners were the Phoenicians (Diodorus 5,35,4) and the Greeks (Herodotus $1,163 ; 4,152)$.
The capital of Tartessos lay between the two mouths of the river Baetis (Strabon 3,1,9; 3,2,11; Pausanias 6,19,3). The Baetis was tidal and Iberia's largest river (Pausanias 6,19,3). Baetica was the ancient Roman name of Andalusia (cf. Pliny 3,6). So it is reasonable to identify the Baetis with the Guadalquivir and to locate the capital of Tartessos within the Donana National Park.

\subsection{Dating}

The Tartessians had knowledge of writing (Strabon 3,1,6). This knowledge was brought to Iberia by Phoenician colonists. The culture of Tartessos ended about 550 BC (Herodotus $1,163)$.

\section{TARSHISH}

\subsection{Sources}

We know about Tarshish by inscriptions of the Assyrian king Asarhaddon and by several books of the bible. These include Genesis (10,1-4), 1 Kings (10,22; 22,49), 1 Chronicles (1,5-7), 2 Chronicles $(9,21 ; 20,36)$, Psalms $(48,8 ; 72,10)$, prophets Isaiah $(2,16 ; 23,1 ; 23,6 ; 23,14 ; 60,9$; $66,19)$, Jeremiah $(10,9)$, Ezekiel $(27,12 ; 27,25$; $38,13)$, and Jonah $(1,3 ; 4,2)$.

\subsection{Trade}

\subsection{Localization}


Tarshish traded with several precious metals (1 Kgs 10,22; 2 Chr 9,21; Ezek 27,12), especially with silver (1 Kgs 10,22; 2 Chr 9,21; Isa 60,9; Jer 10,9; Ezek 27,12). Among its trade partners were the Phoenicians (1 Kgs 10,22; 2 Chr 9,21; Ezek 27,12) and the Hebrews (1 Kgs 10,22; 2 Chr 9,21).

\subsection{Localization}

Tarshish was a grandson of Japhet (Gen 10,2-4; $1 \mathrm{Chr}$ 1,5-7). This means that Tarshish was a state either in Europe or Anatolia. King Solomon's ships brought apes from Tarshish (1 Kgs 10,22; 2 Chr 9,21). This means that Tarshish was near Gibraltar, because Gibraltar is the only place in Europe and Anatolia where there live apes. With the Greek ending -os, the name Tarshish or Tarsis becomes Tarsisos or, as it is easier to pronounce, Tarsessos or Tartessos.

\subsection{Dating}

Tarshish existed already during the time of king Solomon in the tenth century BC (1 Kgs 10,22; $22,49 ; 2 \mathrm{Chr} 9,21 ; 20,36)$ and existed at least until the time of prophet Ezekiel in the sixth century BC (Ezek 27,12; 27,25; 38,13). All this confirms the view of Eusebius $(11,17)$ that Tarshish and Tartessos were identical.

\section{ATLANTIS}

\subsection{Sources}

We know about Atlantis by the Greek philosopher Plato. Plato's Atlantis tale (Timaios 20d-27a; Critias 106a-121c) includes philosophical fiction to describe his fictitious ideal state in the case of war (Tim 19b-20c).

\subsection{Trade}

Atlantis was a commercial centre (Crit 117e) and rich in metals (Crit 114e).

\subsection{Localization}

Atlantis lay in the Atlantic Sea beyond the pillars of Heracles (Tim 24e; Crit 108e), this means beyond Gibraltar (cf. Pliny 3,4). Atlantis consisted of ten countries (Crit 113e-114a; $116 \mathrm{e} ; 119 \mathrm{c})$. The second largest and easternmost of these countries extended from the Gadeirean country to the pillars of Heracles (Crit 114b). This means that it extended from the city of Cadiz to Gibraltar. The capital of Atlantis lay in the largest of the ten countries (Crit 114a). The capital lay at a south coast (Crit 118a-b) and within a large rectangular plain (Crit 118c). West of Cadiz there is only one rectangular plain at a south coast. This is the valley of the Guadalquivir southwest of Sevilla. The capital lay close to the coast (Crit 113c; 115d). So it lay in the Donana National Park.

\subsection{Dating}

There were olive trees on Atlantis (Crit 115b). The Atlanteans sacrificed bulls (Crit 119d-120a) and had knowledge of writing (Crit 119c-d). The plain of Atlantis included a system of channels (Crit 118d-e). Olive trees, sacrifice of a bull, writing, and channels are known in Iberia only since the Phoenician colonization. The native name of one of the first kings of Atlantis was Gadeiros (Crit 114b). Gadir is a Phoenician word and means "fencing" (Pliny 4,120). It was the Phoenician name of the city of Cadiz. 